\title{
Bilateral chylothorax complicating bibasilar pneumonia: A case report
}

\author{
Churchill Lukwiya Onen, Bethuel Nderingo Ndosi, Martin Sibanda, Nuru Said Omari, Jane Njeri \\ Gitau, Richard Alasai J osiah
}

Gaborone Private Hospital, Botswana

Correspondence: Churchill L Onen. Address: Gaborone Private Hospital, Botswana. E-mail: onenkede@info.bw

Received: July 28, 2015

DOI : $10.5430 /$ crim.v2n4p4

Accepted: August 17, 2015

URL: http://dx.doi.org/10.5430/crim.v2n4p4

\section{Abstract}

A 24-year-old previously healthy, HIV-negative lady with acute respiratory symptoms for one week, presented with bilateral chylous pleural effusions and bibasilar pneumonia. She responded rapidly to antimicrobial therapy and bilateral tube thoracostomies. Analysis of a sample of right pleural fluid confirmed exudative chylous effusion. No organisms were identified on fluid microscopy or culture. The left pleural fluid was macroscopically chylous. She had no features of tuberculosis. Bilateral chylothorax complicating bibasilar pneumonia is considerably rare.

\section{Keywords}

Bilateral, Chylothorax, Bibasilar, Pneumonia

\section{I ntroduction}

Despite its recognition as far back as the seventeenth century, chylothorax remains a curiosity to most clinicians ${ }^{[1]}$. It is characterized by milky pleural effusion, often exudative but sometimes transudates and frequently unilateral. Malignancy, particularly lymphoma, is the most common cause of chylothorax. The next common cause is trauma, including chest surgery ${ }^{[2]}$. In Botswana, Verma et al. described a case of a 40-year-old man with HIV-associated Kaposi's sarcoma and bilateral chylothorax at Princess Marina Hospital two years ago ${ }^{[3]}$. Bilateral chylothorax secondary to tuberculosis has been described in a teenage girl in India ${ }^{[4]}$. But bilateral chylothorax complicating bacterial pneumonia is extremely rare.

\section{Case report}

DS, a 24-year-old lady was in excellent health until a week before entry to the Emergency Room (ER) of Gaborone Private Hospital (GPH) after developing dry cough. Treatment with a course of Amoxycillin/Clavullanate $1 \mathrm{~g}$ BD by a general practitioner reportedly resulted in little improvement. A day before entry, she developed bilateral pleuritic chest pains, dyspnea and worsening dry cough. Triage revealed normal oxygen saturation of $98 \%$ on ambient air, temperature $36.7^{\circ} \mathrm{C}$, blood pressure 113/76 mmHg with sinus tachycardia of $104 \mathrm{bpm}$. Chest X-rays done after initial evaluation in ER showed bilateral pleuropulmonary shadowing with meniscus signs consistent with large right-and medium-sized left pleural effusions and probable basal pneumonia (see Figure 1). Contrast-enhanced computed tomography scans of the chest and 
lungs taken immediately after review of chest X-rays confirmed bilateral pleural effusions, larger on the right than the left pleural space. There were pneumonic changes in both lung bases. The right side had consolidation with air-bronchogram, whereas the left lower zone had consolidation with atelectasis. There was no tracheal, parabronchial, mediastinal or hilar lymphadenopathy (see Figures $2 \mathrm{a} \& 2 \mathrm{~b}$ ). She had history of asthma in childhood but apparently went into remission at the age of 12 years. There was no history of chest trauma, surgery, strain or pulmonary tuberculosis. She did not smoke cigarettes or use alcohol. Her father has hypertension and the mother is diabetic.

Figure 1. Initial chest x-ray (postero-anterior view taken on 09/06/2015) showed bilateral basal pleuro-pulmonary shadowing with meniscus signs, indicative of bilateral pleural effusions, probable pneumonia and atelectasis

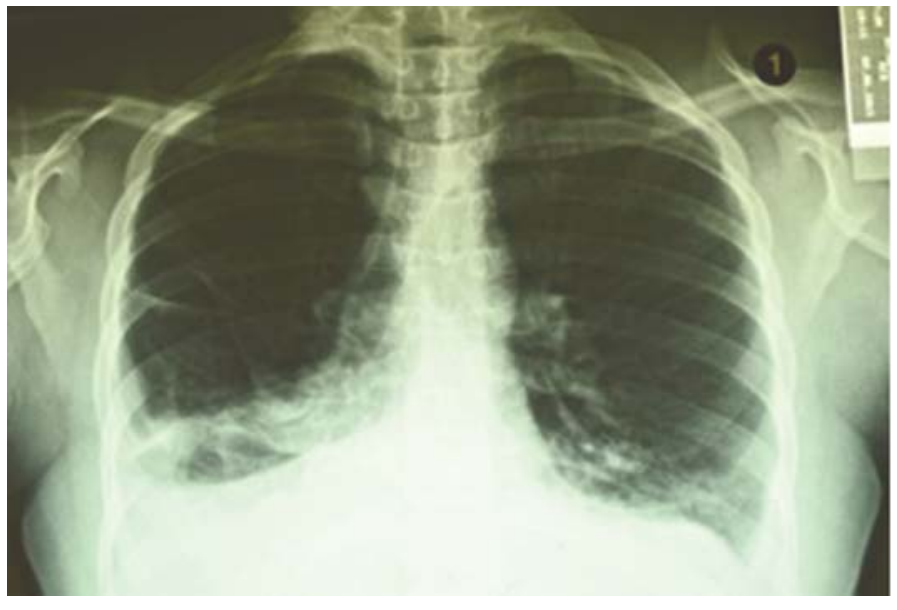

Figure 2. Computed tomography scans of the chest and lungs taken immediately after above chest X-ray study confirmed bilateral large pleural effusions, larger on the right side with right basal pneumonic consolidation with air bronchogram. Less degree of pneumonic changes was evident in the left lower lobe, associated with bilateral atelectasis. There were no masses, mediastinal or hilar lymphadenopathy

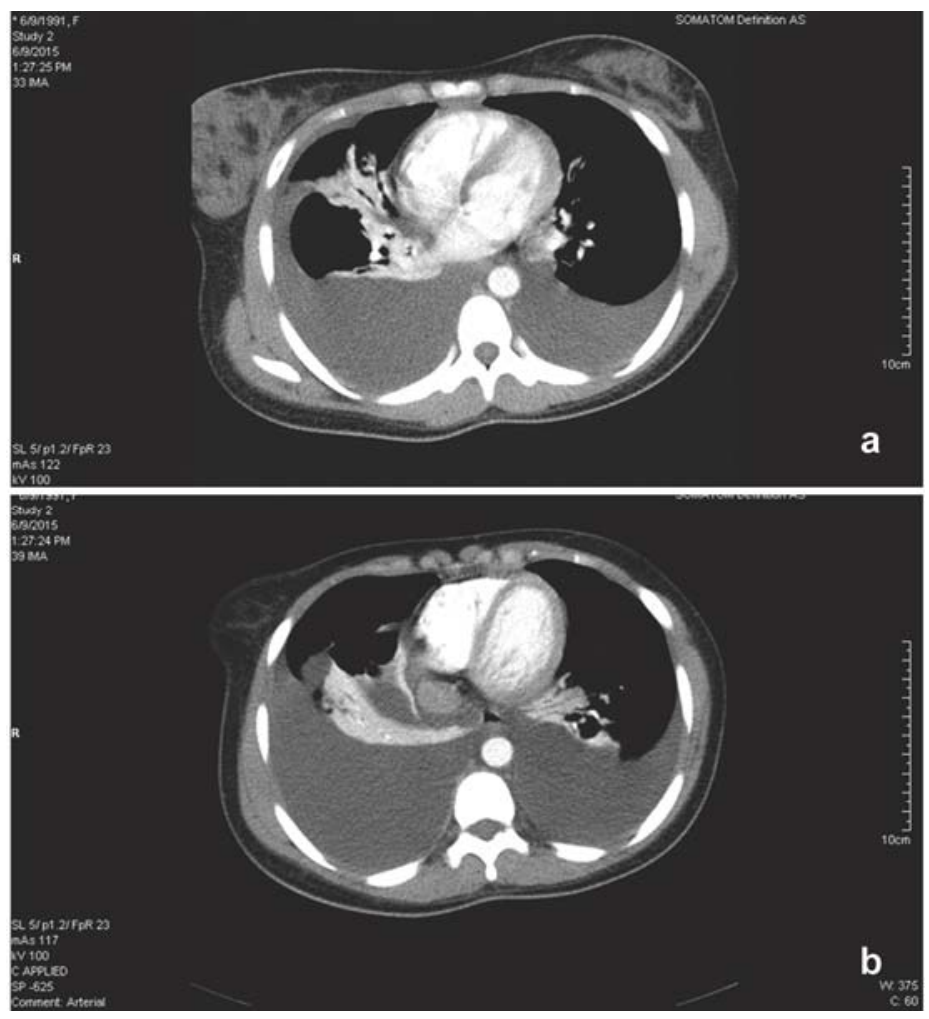

Pertinent findings on physical examination included a pleasant left-handed young lady in good general condition with no pallor, peripheral lymphadenopathy, pyrexia or stigmata of HIV infection. Her chest was symmetrical with central trachea. There was no chest wall tenderness. Both infrascapular and lower axillary regions were stony dull on percussion, with absent breath sounds. No crepitation, bronchial breathing or pleural rub was heard. Her heart and abdomen were clinically normal. 
Peripheral blood indices were normal with haemoglobin concentration of $12.5 \mathrm{~g} / \mathrm{dl}$, MCV $77.9 \mathrm{fl}, \mathrm{MCH} 25.1 \mathrm{pg}$, MCHC $32.2 \mathrm{~g} / \mathrm{dl}$, platelets $366 \times 10^{9} / \mathrm{L}$, WBC $11.6 \times 10^{9} / \mathrm{L}$ (Neutrophils 8.3, Lymphocytes 2.27, Monocytes 0.67, Eosinophils 0.34, Basophils 0.02) and erythrocyte sedimentation rate of $12 \mathrm{~mm}$ in the first hour. C-reactive protein was slightly raised to $5.4 \mathrm{mg} / \mathrm{L}$ (normal $<5$ ). Serum sodium was $136 \mathrm{mmol} / \mathrm{L}$, potassium $4.9 \mathrm{mmol} / \mathrm{L}$, chloride $105 \mathrm{mmol} / \mathrm{L}$, total bicarbonate $24 \mathrm{mmol} / \mathrm{L}$, urea $3.4 \mathrm{mmol} / \mathrm{L}$, creatinine $64 \mu \mathrm{mol} / \mathrm{L}$ and eGFR $>89 \mathrm{mls} / \mathrm{min}$. HIV test was negative.

Diagnostic right thoracentesis yielded 10 millilitres (mls) of milky fluid, consistent with chylothorax (see Figure 3). The left pleural effusion was spared diagnostic aspiration, pending tube thoracostomy. Right pleural fluid analysis revealed a chylous exudate with protein content of $38 \mathrm{~g} / \mathrm{L}$, fluid lactate dehydrogenase $183 \mathrm{i \mu} / \mathrm{L}$, fluid triglycerides of $46.3 \mathrm{mmol} / \mathrm{L}$, cholesterol $3.02 \mathrm{mmol} / \mathrm{L}$ and adenosine deaminase of $5.9 \mathrm{i} \mu / \mathrm{L}$ (normal 0.7-24). Pleural fluid microscopy revealed no organisms and bacterial culture yielded no growth after 48 hours. Treatment with intravenous Ceftriaxone 2 G Q12 hourly and oral Paracetamol 1 G TID were commenced.

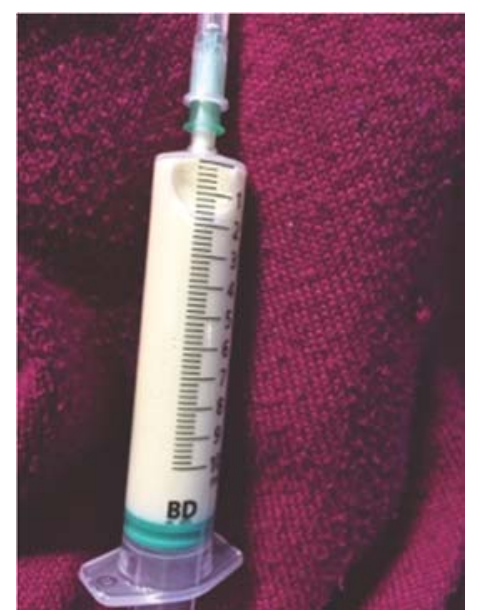

Figure 3. A $10 \mathrm{ml}$ syringe used for diagnostic right thoracentesis, filled with milky chylous pleural fluid
Proposed bilateral tube thoracostomies were discussed with the patient and her informed consent obtained. The next day, intramuscular Pethidine $50 \mathrm{mg}$ was administered thirty minutes prior to procedures. Bilateral intercostal chest drains (ICDs) were inserted by the bedside starting with the right side; the patient resting on her back on a reclining bed to about 45 degrees, the ipsilateral arm in abduction and hand placed behind her head. Both sites were prepared and draped aseptically. A total of $10 \mathrm{mls}$ of $1 \%$ lignocaine was infiltrated through skin to the pleura to achieve local and pleural block. A $10 \mathrm{~mm}$ stab wound was made to the anaesthetized skin using a sharp number 11 surgical blade followed by blunt dissection to the pleural space using a pair of scissors. A 24 French gauge ICD tube was placed in the 4th intercostal space in the mid-axillary line in a postero-basal direction and secured with purse-string 2.0 nylon sutures (see Figure 4). Under water-seal bottle was connected to each thoracostomy tube. Despite copious

flow of frankly milky chylous fluid on the right side and blood-stained chylous fluid on the left side, drainage was tolerated well. The patient remained afebrile and maintained oxygen saturation above $98 \%$ while breathing room air. Over the ensuing 72 hours, a total of 1.38 litres of chylous pleural fluid drained. By the third day, the right pleural fluid drainage had dropped to $100 \mathrm{mls}$, while the left tube drained $80 \mathrm{mls}$. Follow-up chest X-rays showed sharp costophrenic angles and hemidiaphragms (see Figure 5). Both ICD tubes were removed on the fourth postoperative day without any complications. Apart from mild pains at thoracostomy sites, she remained subjectively well without pyrexia or dyspnea. Oxygen saturation was $94 \%$ on room air. She was discharged in good general condition on oral antimicrobials and mild analgesics.

Figure 4. Follow-up portable antero-posterior chest radiograph taken on 10/06/2016 demonstrated bilateral chest drains without pneumothorax or surgical emphysema. There was marked reduction of bilateral pleural effusions with adequate lung expansions

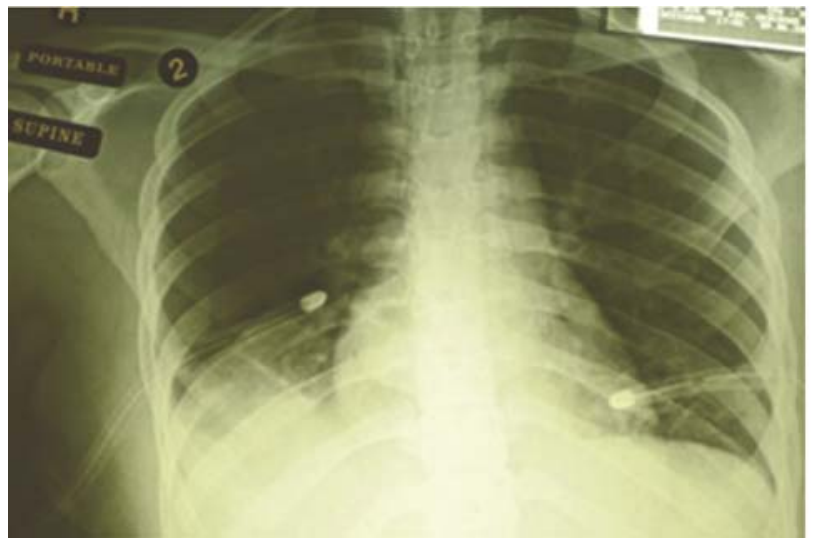

ISSN 2332-7243 E-ISSN 2332-7251 
Figure 5. Follow-up portable antero-posterior chest radiograph taken on 12/06/2015 showed resolution of bilateral pleural effusions with adequate expansion of the lungs

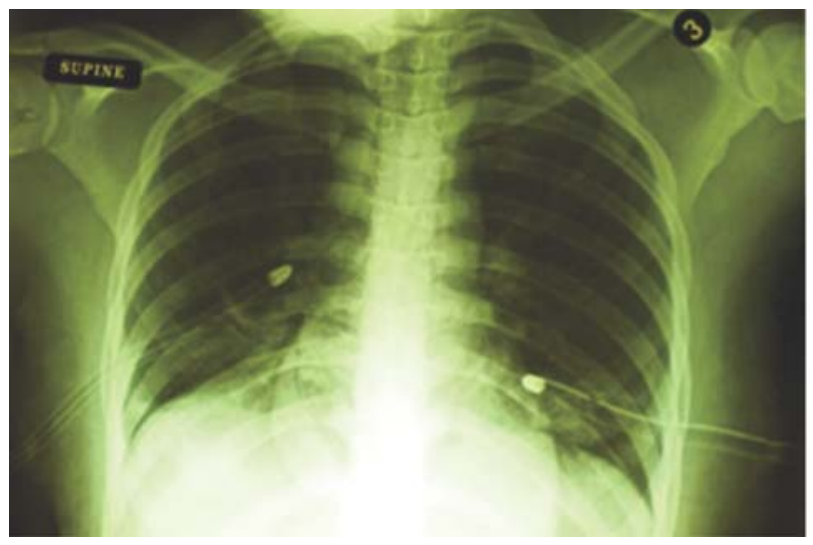

Outpatient review five days after discharge revealed that she was subjectively well apart from slight residual cough but she had no fever or shortness of breath. Stitches were removed from ICD sites and dry dressings applied. Physical examination revealed good general condition with axillary temperature of $36.2^{\circ} \mathrm{C}$. She had no clinical signs of residual or recurrent pleural effusions on either side. There was no subcutaneous emphysema. Her pulse rate was $85 \mathrm{bpm}$ and blood pressure was $110 / 76 \mathrm{~mm} \mathrm{Hg}$ in the supine position. The heart and abdomen were clinically normal. The final chest X-rays taken 11 days after the first examination demonstrated clear lungs with no residual pleural effusions. Both lungs were well expanded with clear costo-phrenic angles (see Figures $6 \mathrm{a} \& 6 \mathrm{~b}$ ). She signed informed consent form for publication of her case, witnessed by her mother. She was discharged for review in 6-12 months.
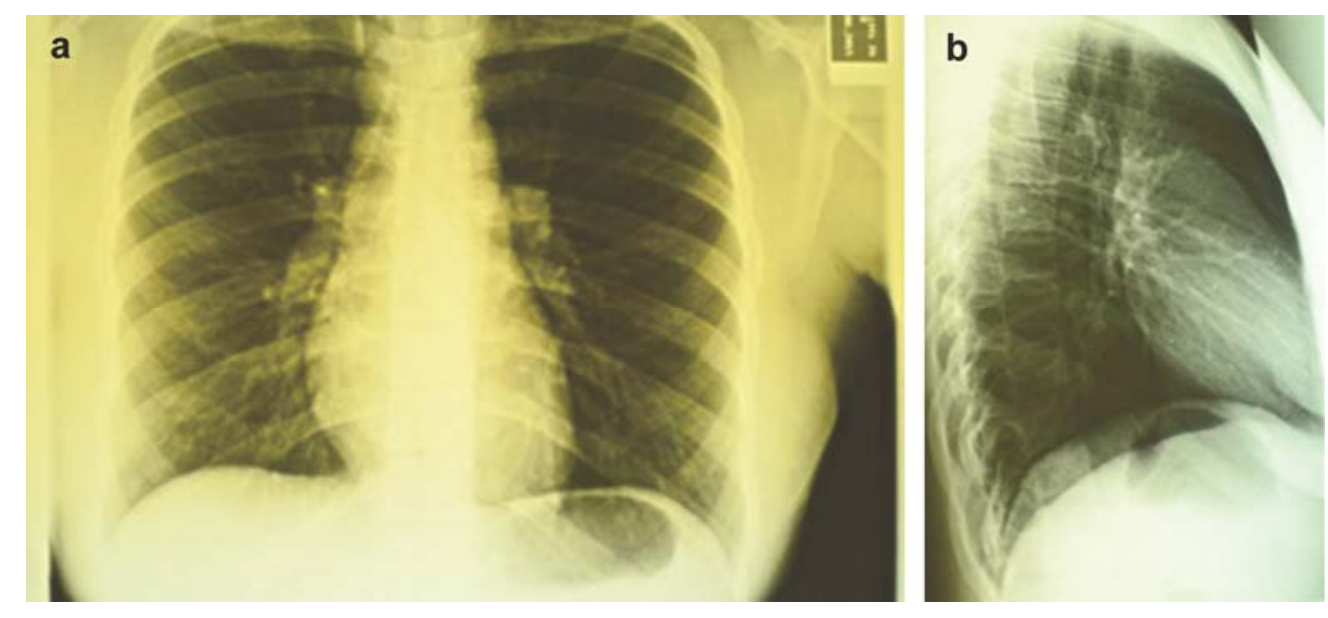

Figure 6. a. Final follow-up chest radiographs (PA and lateral) taken on 18/06/2015 demonstrated normal appearances of both lungs. Chest drains had been removed. Costo-phrenic angles appeared sharply defined; b. Lateral view of final chest radiograph taken on $18 / 06 / 2015$

\section{Discussion}

Nontraumatic, nonmalignant causes of chylothorax include tuberculosis, histoplasmosis, amyloidosis, sarcoidosis, lymphangiomyomatosis, filariasis, superior vena cava obstruction, retrosternal goiter, haemangiomatosis and yellow nail syndrome ${ }^{[5]}$. Medical devices such as central venous pressure lines and pacemakers are potential iatrogenic causes of chylothorax. Diagnostic criteria ${ }^{[6]}$ for chylous pleural effusion include fluid triglycerides $>1.24 \mathrm{mmol} / \mathrm{L}$ and cholesterol content $<5.18 \mathrm{mmol} / \mathrm{L}$. Lipoprotein analysis for detection of chylomicrons is not routinely performed.

Anatomically, the thoracic duct ascends into the thorax from the cisterna chyli through the aortic hiatus at the level of the tenth to twelfth thoracic vertebra and travels to the right of the vertebral column. At the level of the fifth or sixth thoracic 
vertebra, the thoracic duct crosses posterior to the descending aorta and the aortic arch into the left posterior mediastinum. It courses anterior to the subclavian artery, within Poirier's triangle, and exits the superior thoracic aperture in the neck. After exiting the thorax, it forms an arch anterior to the anterior scalene muscle and turns inferiorly to terminate at the junction of the left subclavian and internal jugular veins ${ }^{[7]}$. The thoracic duct receives nonchylous lymph from tributaries that drain the pulmonary parenchyma and parietal pleura ${ }^{[8]}$. However, the course of the thoracic duct has wide anatomic variations. The pattern described above is true only in approximately $65 \%$ of the population ${ }^{[9]}$. Some individuals have two thoracic ducts within the mediastinum, and others have single duct that empties into the right venous system.

Thoracic duct injury below T5 results in right-sided chylothorax (accounting for $50 \%$ of chylothorax), whereas injury above T5 level results in left-sided chylous effusion (35\%). Injury of the thoracic duct at T4-T6 level results in bilateral effusions. Chylothorax represents about $2 \%-3 \%$ of all pleural effusions in adults. Bilateral chylothorax occurs when leakage occurs at a level between the third and sixth thoracic vertebrae. There have been case reports of bilateral chylothorax associated with light physical exercise such as stretching or minor trauma by seat belt ${ }^{[10-12]}$.

Approximately $5 \%$ to $10 \%$ of chylothoraces have no immediate causative factor at the time of presentation and may therefore be regarded as idiopathic ${ }^{[13]}$. Pleurisy associated with tuberculosis, pneumonia or lupus may obstruct intercostal lymphatic channels. In this patient, the suggestion of intercostal lymphatic obstruction as a possible explanation for bilateral chylothorax, is speculative and inadequate since lymphangiography (LAP) with follow-up CT scans were not performed. However, her excellent recovery and lack of LAP at the facility relegated the procedure. Moreover, drainage of frankly milky triglyceride-rich fluids by both thoracostomy tubes argues against obstruction of non-chylous intercostal lymphatic channels.

This patient represents an unusual complication of bilateral pneumonia. We speculate that she had double thoracic ducts within the mediastinum to reasonably explain the occurrence of bilateral chylous pleural effusions associated with bibasilar community acquired pneumonia (CAP). Her history was short and response to antimicrobial therapy rapid, making tuberculosis highly unlikely. She had marginally raised acute phase reactants with mild neutrophilia and elevated C-reactive protein but erythrocyte sedimentation rate was surprisingly normal. It is debatable whether these results were modulated by her earlier treatment with antimicrobials by the general practitioner. Although follow-up postero-anterior chest X-rays taken about two weeks after admission showed complete radiological clearance of the pneumonia without discernible residual pleural effusion, this observation must be interpreted with some caution. Without lateral decubitus films or chest ultrasound scans in her final evaluation, small residual pleural effusions could have been missed. Repeat CT scans could not be clinically justified. The pathognomonic pleural fluid characteristics consistent with exudative chylous effusions and her rapid response to conservative treatment made it unnecessary to demonstrate the site of possible chylous leakage by thoracoscopy. Lymphangiography with post-contrast CT scans is not available in our facility, and might have been difficult to justify. To our knowledge, this is the first reported case of chylothorax associated with pneumonia in Botswana. Failure to isolate causative organism might have been compounded by antimicrobial effects of chyle and prior use of antibiotics. Despite the absence of definitive microbiological diagnosis of her pneumonia, Streptococcus pneumoniae, the most common cause of CAP is suspected. She responded promptly to treatment with Ceftriaxone without any strong indication for arterial blood gas analyses. She had community-acquired pneumonia severity index total score of 24, translating to Class I severity with excellent prognosis.

\section{References}

[1] Chylothorax JW. Brief review of the literature. Report of three nontraumatic cases. Ann Int Med. 1944; $21: 669$.

http://dx.doi.org/10.7326/0003-4819-21-4-669

[2] Valentine VG, Raffin TA. The management of chylothorax. Chest. 1992; 102: 586-591. http://dx.doi.org/10.1378/chest.102.2.586 
[3] Verma K, Haverkamp M, Kayembe M, et al. Chylothorax associated with non-endemic Kaposi's sarcoma. S Afr J HIV Med. 2013; 14(3): 141-143. http://dx.doi.org/10.7196/sajhivmed.933

[4] Kant S, Verma SK, Anand SC, et al. Development of bilateral chylothorax in a younger female secondary to tuberculosis. Lung India. 2011; 28(1): 56-59. http://dx.doi.org/10.4103/0970-2113.76303

[5] Hillerdal G. Chylothorax and pseudochylothorax. Eur Respir J. 1997; 10: 1157-1162. PMid:9163662 http://dx.doi.org/10.1183/09031936.97.10051157

[6] Light RW. Clinical Practice. Pleural effusion. N Engl J Med. 2002; 346: 1971-1977. PMid:12075059 http://dx.doi.org/10.1056/NEJMcp010731

[7] Nair SK, Petko M, Hayward MP. Aetiology and management of chylothorax in adults. Eur J Cardiothorac Surg. 2007; 32(2): 362-369. PMid:17580118 http://dx.doi.org/10.1016/j.ejcts.2007.04.024

[8] Weidner WA, Steiner RM. Roentgenographic demonstration of intrapulmonary and plural lymphatics during lymphangiography. Radiology. 1971; 100: 533. PMid:4327846 http://dx.doi.org/10.1148/100.3.533

[9] Davis M. A statistical study of the thoracic duct in man. Am J Anat. 1915; 171:212. http://dx.doi.org/10.1002/aja.1000170203

[10] Garcia-Aparicio J, Herrero-Herrero J-I, Corral-Gudino L, et al. Bilateral idiopathic chylothorax associated with light physical exercise. J Res Med. 2009; 2: 68-69. http://dx.doi.org/10.1016/j.rmedc.2008.10.017

[11] Reilly KM, Tsou E. Bilateral chylothorax: a case report following episodes of stretching. JAMA. 1975; 233: $536-537$. http://dx.doi.org/10.1001/jama.1975.03260060046020

[12] Agrawal V, Doelken P, Sahn SA. Seat belt-induced chylothorax. A cause of idiopathic chylothorax? Chest. 2007 ; $132: 690-692$. http://dx.doi.org/10.1378/chest.07-0535

[13] Doerr CH, Allen MS, Nichols FC, et al. Etiology of chylothorax in 203 patients. Mayo Clin Proc. 2005; 80: 868-870. PMid:16007891 http://dx.doi.org/10.4065/80.7.867 